\section{A) Check for updates}

Cite this: Mater. Adv., 2021, 2, 3770

Received 2nd February 2021, Accepted 26th April 2021

DOI: $10.1039 / \mathrm{d} 1 \mathrm{ma} 00099 \mathrm{c}$

rsc.li/materials-advances

\title{
Self-healing polymer-clay hybrids by facile complexation of a waterborne polymer with a clay $\dagger$
}

\author{
Aranee (Pleng) Teepakakorn (D) ${ }^{a}$ and Makoto Ogawa (D) *b
}

\begin{abstract}
Water-induced self-healing materials were prepared by the hybridization of a water-soluble polymer, poly(vinyl alcohol), with a smectite clay via mixing in an aqueous medium and subsequent casting. Without using chemical crosslinking agents or heat treatment, the poly(vinyl alcohol)-clay hybrid adhered strongly to substrates, showing self-healing when immersed in water $\left(25^{\circ} \mathrm{C}\right)$. The healing was completed within 1 min by soaking a damaged poly(vinyl alcohol)-clay film under such conditions as in cold water $\left(2{ }^{\circ} \mathrm{C}\right)$, simulated seawater, steam, $\mathrm{HCl}$ solutions $(\mathrm{pH}=1)$ and $\mathrm{NaOH}$ solutions $(\mathrm{pH}=14)$. The healing was seen repeatedly 10 times.
\end{abstract}

\section{Introduction}

The protection of material surfaces against damage by external mechanical forces is crucial for the sustainable use of materials, and therefore, materials covered by protective layers that possess mechanical toughness and healing ability have been investigated. Self-healing is a capability of the protective layer to recover from its damages involving the rupture of chemical and/or physical bonds. ${ }^{1-3}$ Among materials showing healing phenomena, selfhealing polymers have been extensively investigated for various applications such as energy storage/conversion devices, ${ }^{4,5}$ electronic medical devices (electronic and sensing skin), ${ }^{6,7}$ and protective coating (anticorrosion and antifouling) ${ }^{8,9}$ in order to extend materials' lifetime and reduce wastes. According to the healing mechanism, self-healing polymers are classified into autonomous and nonautonomous systems in which the damages are healed without and with the assistance of external stimuli, respectively. Such external stimuli as microwave irradiation, ${ }^{10,11}$ UV-Visible irradiation, ${ }^{12,13}$ heat,${ }^{14,15}$ magnetic field, ${ }^{16} \mathrm{pH},{ }^{17}$ and addition of

\footnotetext{
${ }^{a}$ School of Molecular Science and Engineering, Vidyasirimedhi Institute of Science and Technology (VISTEC), 555 Moo 1 Payupnai, Wangchan, Rayong 21210, Thailand

${ }^{b}$ School of Energy Science and Engineering, Vidyasirimedhi Institute of Science and Technology (VISTEC), 555 Moo 1 Payupnai, Wangchan, Rayong 21210, Thailand. E-mail: makoto.ogawa@vistec.ac.th

$\dagger$ Electronic supplementary information (ESI) available: XRD patterns of 4 and 5 PVA-SWF, microscopy images of re-healing 1.80 PVA-SWF, microscopy images of engraved 1.80 PVA-SWF with the thickness of 1 and $2 \mu \mathrm{m}$, photographs of 1.80 PVA-SWF coated on the hook, temporal evolution of defect 1.80 PVA-SWF, temporal evolution of engraved 0.36, 1.08, 1.80, 4 and 5 PVA-SWFs, SEM image of SWF, schematic of shear lap test, relationship between the shear load and the displacement, weights of PVA-SWF film before and after immersion in water. See DOI: $10.1039 / \mathrm{d} 1 \mathrm{ma} 00099 \mathrm{c}$
}

organic solvents ${ }^{18}$ have been used for healing. These stimuli require energy consumption, addition of active chemical reagents and chemical modification of polymer chains.

As an alternative ecofriendly stimulus, self-healing polymer in water has been studied and used as a protecting layer for civil engineering products, biomaterials and electronic devices not only under ambient conditions but also in underwater applications. ${ }^{19}$ Water is used to facilitate the reversible molecular interaction/ bonding between the functional groups on the polymer backbone. A variety of polymers have been designed for water-induced selfhealing, for example, catechol-functionalized polymers with or without complexation with polymer-based boronic ester, ${ }^{20,21}$ poly(vinylidene fluoride-co-hexafluoropropylene), ${ }^{22}$ an assembly of cationic and/or anionic polymers, ${ }^{23,24}$ and nonionic water-soluble polymers. ${ }^{25-33}$ In order to "insolubilize" water-soluble polymers and to achieve mechanical strength and chemical stability, such methods as the addition of chemical crosslinking agents, heat treatment and introduction of nanofillers are known. For the practical use of self-healing materials, mechanical strength, chemical stability, adhesion to the solid substrate and ecofriendly preparation method are expected in addition to healing performances. Materials with healing ability under various conditions are also worth developing.

Nanofillers have been used to modify the properties of various polymers. ${ }^{34}$ Smectite, which is a group of layered clay minerals with 2:1 type phyllosilicate structure, is one of the nanosheet fillers used extensively as a polymer additive. Interactions with smectites and the properties of the resulting polymer-clay hybrids have been investigated for various polymers including the water-soluble ones. ${ }^{35}$ The in situ polymerization of acrylamide in the presence of a smectite was reported to obtain the hydrogel (named $\mathrm{NC}$ gel), which showed 
mechanical robustness, stability in water and self-healing property. ${ }^{36-38}$ In the present study, a hybrid of a water-soluble polymer, poly(vinyl alcohol), and a smectite clay was prepared to obtain a coating, which showed self-healing behavior under different conditions. The polymer-clay composition was shown to be a key parameter to control the solubility of water-soluble polymers, degree of swelling, and self-healing of the resulting product.

\section{Experimental section}

\section{Materials}

Poly(vinyl alcohol) (abbreviated as PVA; $n=2000$ ), rhodamine 6G (abbreviated as R6G) and sodium chloride (abbreviated as $\mathrm{NaCl}$ ) were purchased from Tokyo Chemical Industry Co., Ltd, Japan. A synthetic hectorite (Sumecton SWF, abbreviated as SWF, the cation exchange capacity (CEC) of $70 \mathrm{mmol} / 100 \mathrm{~g}$ ) was donated by Kunimine Ind. Co. Ltd, Japan. Sodium hydroxide (abbreviated as $\mathrm{NaOH}$, pellets $\geq 98 \%$ purity) was purchased from Sigma-Aldrich, USA. Hydrochloric acid (abbreviated as $\mathrm{HCl}, 37 \%$ ) was obtained from Merck KGaA from Germany. All the chemicals were used without further purification. Water was purified using a Milli-Q system (18 $\mathrm{M} \Omega \mathrm{cm}^{-1}$, Millipore) before use. Microscopic borosilicate glass slides were obtained from BRAND GMBH + Co. Kg, Germany.

\section{Sample preparation}

SWF $(2.25,1.23,0.85,0.43$ and $0.36 \mathrm{~g}$ for the weight ratios of $\mathrm{PVA} / \mathrm{SWF}=0.36,1.08,1.80,4$ and 5 , respectively) was dispersed in $160 \mathrm{ml}$ of DI water by magnetic stirring for 1 day. R6G ( $1 \mathrm{mmol} / 100 \mathrm{~g}$ clay) was mixed with the SWF suspension in order to stain the samples for naked eye observations. Then, an aqueous PVA solution (40 ml) was added to the R6G-SWF suspension. The amount of PVA was $0.81,1.33,1.53,1.74$ and $1.78 \mathrm{~g}$, which corresponded to the weight ratios of PVA/SWF = $0.36,1.08,1.80,4$ and 5 , respectively. The mixture was magnetically stirred for another 1 day to obtain a homogeneous suspension. The aqueous suspension of SWF and the PVA solution containing $1 \mathrm{mmol} / 100 \mathrm{~g}$ R6G were also prepared as references. Before casting, all the suspensions were sonicated for $30 \mathrm{~min}$ to eliminate air bubbles. Borosilicate glass substrate $(12 \times 25 \mathrm{~mm})$ was cleaned with an aqueous solution of $\mathrm{NaOH}$ (pH 10-11) for 1-2 days at room temperature and dried in air. An aliquot $(250 \mu \mathrm{l})$ of the PVA-SWF suspensions (weight ratio of $\mathrm{PVA} / \mathrm{SWF}=0.36,1.08,1.80,4$ and 5 ; the samples were designated as 0.36 PVA-SWF, 1.08 PVA-SWF, 1.80 PVA-SWF, 4 PVA-SWF and 5 PVA-SWF), SWF suspension or PVA solution were casted onto the glass substrate using a micropipette and dried at a constant temperature $\left(25-26{ }^{\circ} \mathrm{C}\right)$ and humidity (70-80\% RH) in a plastic closed box with the dimension of $24^{\prime \prime} \times 14^{\prime \prime} \times 18.5^{\prime \prime}$ for the slow evaporation of water to achieve uniform distribution and the orientation of clay particles parallel to the substrate. The film thickness was determined using a surface profilometer (Dektak XT, Bruker) to be $4.9 \pm 0.8,4.8 \pm 0.8,5.0 \pm 0.9,5.2 \pm 0.1$ and $5.2 \pm 0.2 \mu \mathrm{m}$ for
$0.36,1.08,1.80,4$ and 5 PVA-SWF, respectively. The depth profile along the length of the engraved 0.36, 1.08, 1.80, 4 and 5 PVA-SWF films is shown in Fig. S6 (ESI $\dagger$ ). Two ridges were formed along the engraved part as seen in all the temporal evolution plots. These two ridges were not taken into account for the thickness measurement.

\section{Healing test}

Films were engraved by scalpel and the size of the notch was approximately $30 \mu \mathrm{m}$. The engraved film was healed by immersing the samples into water (R.T.), cold water $\left(2{ }^{\circ} \mathrm{C}\right)$, simulated

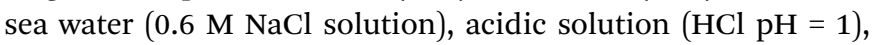
basic solution $(\mathrm{NaOH} \mathrm{pH}=14)$, steam and a hydrothermal condition (heating at $100{ }^{\circ} \mathrm{C}$ under $80 \mathrm{kPa}$ in a kitchen cooker for $2 \mathrm{~h}$ ).

\section{Adhesion test}

The 1.80 PVA-SWF suspension was casted onto the stainlesssteel hook and dried at room temperature (Fig. S4A and D, ESI $\dagger$ ). Water was sprayed to the film and attached to both glass and frosted glass windows (Videos S1 and S2, ESI $\dagger$ ). The hook that was attached to the glass and frosted glass was held for $24 \mathrm{~h}$ before hanging $500 \mathrm{~g}$ of iron balls.

\section{Lab shear test}

The lap shear strength was evaluated using a tensile tester (ADMET eXpert 5604, load cell 50 LB), as shown in Fig. S8 (ESI $\dagger$ ). The 0.36 and 1.80 PVA-SWF suspensions were casted onto a glass substrate with a size of $2.5 \times 2.5 \mathrm{~cm}$. The thickness of 0.36 and 1.80 PVA-SWF films were about $10 \mu \mathrm{m}$. A polypropylene sheet was used to cover the sample at a grip site. Water was sprayed to the sample, and then, an uncoated glass plate was attached and held for $24 \mathrm{~h}$. The adhesion was evaluated by tensile strength testing at a loading rate of $2 \mathrm{~mm} \mathrm{~min}{ }^{-1}$. The measurement was repeated 3 times.

\section{Characterization}

X-Ray diffraction (XRD) patterns were recorded using a Bruker New D8 Advance equipped with $\mathrm{Ni}$ filtered $\mathrm{Cu} \mathrm{K} \alpha$ radiation. Scanning electron micrographs were obtained using a JEOL JSM-7610F field-emission scanning electron microscope (SEM). Prior to the measurements, the samples were coated with platinum to a thickness of 10-12 nm. Elemental mapping images were obtained using an Oxford energy dispersive X-ray fluorescence spectrometer (X-Max $150 \mathrm{~mm}^{2}$ ) equipped with an SEM (JEOL, JSM-7610F). The healing was observed using a microscope (Senterra II, R200-532, Bruker) with a $4 \times$ microscope magnification at $25{ }^{\circ} \mathrm{C}$. The damage depth of the scratched films was evaluated using a profilometer (Dektak $\mathrm{XT}$, Bruker) with a $2 \mu \mathrm{m}$ radius stylus and a stylus force of $0.01 \mathrm{mN}$. 


\section{Results and discussion}

By the simple casting of the suspension containing PVA and SWF onto the glass substrate, a coating of PVA-SWF hybrid was obtained. The XRD patterns of the PVA-SWF films are shown in Fig. 1 . The basal spacing $\left(d_{001}\right)$, which was determined by Bragg's equation from the reflection at the lowest 2 theta region, was larger with the PVA content as 1.63, 2.70 and $4.09 \mathrm{~nm}$ for $0.36,1.08$ and 1.80 PVA-SWFs, respectively. Systematic variation in the interlayer expansion of smectites depending on the amount of the added polymers (poly(vinyl pyrrolidone) or PVP and PVA) was reported. ${ }^{39-43}$ PVA was thought to be preferentially intercalated into the interlayer space of SWF. The interlayer volume of the PVA intercalated SWF was calculated from the composition, the ideal surface area of smectites $\left(750 \mathrm{~m}^{2} \text { per g clay }\right)^{44}$ and the observed gallery height, which was obtained by subtracting the thickness of the silicate layer $(1 \mathrm{~nm})$ from the observed basal spacings $\left(d_{001}\right)$, to be $2.4 \times 10^{-7}, 6.4 \times 10^{-7}$ and $1.2 \times 10^{-6} \mathrm{~m}^{3} \mathrm{~g}^{-1}$ clay for 0.36 , 1.08 and 1.80 PVA-SWFs, respectively. From the interlayer volume and the composition (0.36, 1.08 and 1.8 PVA-SWFs), the density of PVA was estimated to be $1.5-1.6 \mathrm{~g} \mathrm{~cm}^{-3}$, which is slightly higher than the bulk density of PVA $\left(1.01 \mathrm{~g} \mathrm{~cm}^{-3}\right) \cdot{ }^{45}$ The difference is thought to be due to the hydration of the interlayer space, the adsorption of PVA at the external surface of the clay particles and the dense packing of PVA chain in the interlayer space of SWF. The reflection due to the basal spacing was not clearly seen when the weight ratio of PVA-SWF was higher than 4 (Fig. S1, ESI $\dagger$ ), suggesting the further expansion of the interlayer space, which was not detectable by the present measurement.

The photographs of the films taken before and after soaking in water for $24 \mathrm{~h}$ are shown in Fig. 2. By soaking, PVA was dissolved and SWF was dispersed into water, resulting in the disappearance of pure PVA and SWF samples from the substrate. Some parts of 4 and 5 PVA-SWF films were swollen in water, resulting in the partial liberation from the substrate, as

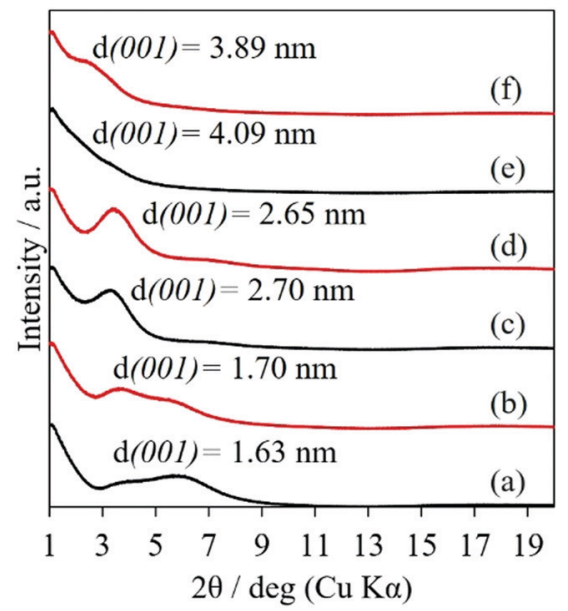

Fig. 1 XRD patterns of 0.36 PVA-SWF ( $a$ and b), 1.08 PVA-SWF (c and d) and 1.80 PVA-SWF (e and f) films before (black) and after (red) the soaking in water for $24 \mathrm{~h}$.

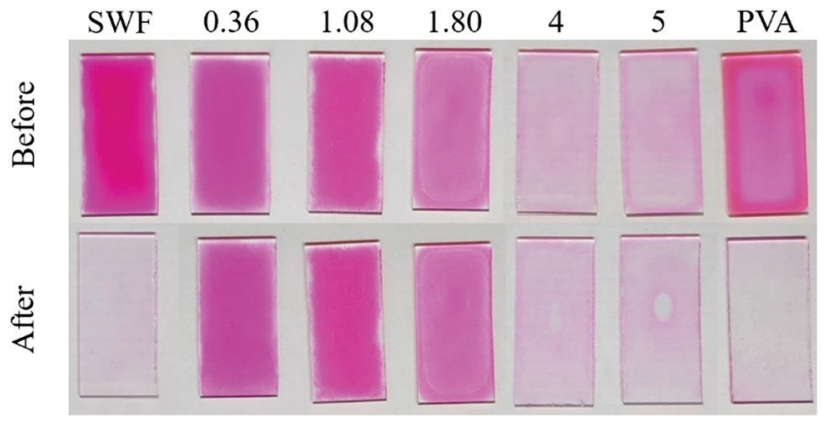

Fig. 2 Photographs of SWF, 0.36 PVA-SWF, 1.08 PVA-SWF, 1.80 PVASWF, 4 PVA-SWF, 5 PVA-SWF and PVA films before (top) and after (bottom) soaking in water for $24 \mathrm{~h}$. The pink color is from the adsorbed R6G.

shown in Fig. 2, which was supported by the weight loss of the film after soaking (Table S1, ESI $\dagger$ ). On the contrary, 0.36, 1.08 and 1.80 PVA-SWF films were adhered to the substrate, as shown by the appearance of the films (Fig. 2, no significant change was seen after immersion). No weight loss/gain was observed upon soaking (Table S1, ESI $\dagger$ ) and the basal spacing did not change (Fig. 1), confirming that $0.36,1.08$ and 1.80 PVA-SWFs were stably adhered to the substrate without swelling. For the oxygen and water vapor barrier film obtained by the hybridization of PVA with smectites, ${ }^{46-49}$ the low oxygen and water vapor permeation was explained as a result of the torturous path by the parallel orientation of clay platelets in the PVA matrix and hydrogen bonding between PVA and clay surface. It was found that the diffusion of water and oxygen decreased as the volume fraction of the clay in the hybrid increased. ${ }^{47-49}$ In the present study, water permeation was thought to be restricted for PVA-SWFs with lower PVA contents, supporting the observed difference in the insolubilization depending on the composition.

Possible roles of the smectite as a crosslinker were proposed for the hydrogels prepared by the in situ polymerization of poly $\left(N\right.$-isopropylacrylamide) and poly $(N, N \text {-dimethylacrylamide })^{37,38}$ and freeze-thawing of $\mathrm{PVA}^{50}$ in the presence of smectites and organically modified smectites, respectively. In those studies, the clay content was within 2-25 wt\%, where possible exfoliation of the clay in the polymers was proposed. However, PVA was intercalated into the interlayer space of smectite for $0.36,1.08$, and 1.80 PVA-SWFs, as shown by the expansion of the interlayer space derived from the XRD results. The stability of PVA-SWF hybrids in water was thought to be due to the ion-dipole interactions and hydrogen bonding between the hydroxyl groups along the PVA chain to the silicate surface as well as the intermolecular hydrogen bonding between the PVA in addition to the restricted water permeation through "torturous path" as discussed before.

The orientation of the silicate layers parallel to the substrate was seen in the SEM images of the cross-section of the 1.80 PVA-SWF film (Fig. 3A-C). The film surface was smooth, and the thickness was $4.3 \mu \mathrm{m}$, which was in agreement with the depth profile analysis using a profilometer (Fig. S6, ESI $\dagger$ ). The silicate nanosheet with a thickness of $1 \mathrm{~nm}$ was not seen clearly from the SEM analysis even at a magnification of 150k (Fig. 3B) 

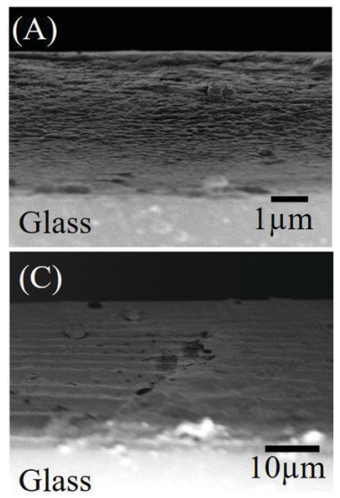
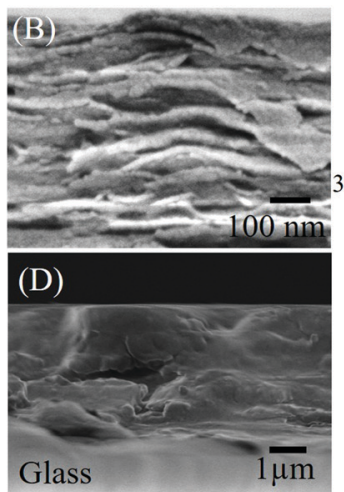

(F)

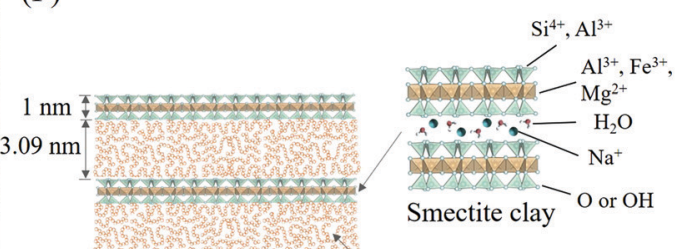

Poly(vinyl alcohol) or PVA

Fig. 3 SEM images of the 1.80 PVA-SWF film cross-section with a thickness of $4.3 \mu \mathrm{m}$ ( $A$ and $B$; magnification of $12 \mathrm{k}$ and $150 \mathrm{k}$, respectively) and $25 \mu \mathrm{m}$ (C; magnification of $2 \mathrm{k}$ ) and the 4 PVA-SWF film cross-section with a thickness of $5 \mu \mathrm{m}$ ( $\mathrm{D}$; magnification of $12 \mathrm{k}$ ) and schematic structure of 1.80 PVA-SWF hybrid (F).

due to the small particle size of SWF (SEM image of SWF is shown in Fig. S7, ESI $\dagger$ ). The uniform distribution of SWF platy particles from the bottom to the surface of the film was suggested for 1.80 PVA-SWF from the layered texture of the film cross section, while the layered texture was not visible for the 4 PVA-SWF film (Fig. 3D). This difference is consistent with the XRD results, where diffraction from the basal plane of SWF was seen for 1.80 PVA-SWF and not seen for the 4 PVA-SWF film. The structural image of 1.80 PVA-SWF is shown in Fig. 3F. The thickness can be varied by using different amounts of the suspension as well as by changing the concentration of the suspension. Fig. 3C shows the SEM images of 1.80 PVA-SWF with a thickness of $25 \mu \mathrm{m}$. In the hybridization of a clay with sodium polyacrylate, the phase separation of the polymer from the precipitated clay was found when the amount of polymer was $30 \mathrm{wt} \% .^{51}$ Such phase separation was not seen for 1.80 PVA-SWF (the amount of polymer was $64 \mathrm{wt} \%$ ), which is an important positive aspect of the present study to achieve homogeneous dispersion of clay particle through the film. Thanks to the homogeneity of the suspension, other coating techniques are also feasible for the preparation of PVA-clay films with varied thickness and shape on various substrates.

Water-induced self-healing of the 1.80 PVA-SWF film was investigated by immersing the engraved film with a thickness of $5.0 \pm 0.9 \mu \mathrm{m}$ in water at room temperature (Fig. 4A). Elemental analysis of the engraved and healed films (Fig. 4B) indicated that both PVA and SWF attended the recovery. The mechanical damage generated the interfacial regions, where the interface polymer chain exhibited a higher degree of freedom than that of the bulk region. ${ }^{52,53}$ Water was used to facilitate the diffusion of PVA across the cut region for the regeneration of the hydrogen bonding between PVA chain and smectite surface and PVA chain itself. The SWF nanosheet did not restrict the diffusion of PVA, but SWF and PVA were diffused together to complete the healing as indicated in the elemental mapping of the scratched/healed part (Fig. 4B). The evolution of the depth along the length of the surface's defect was characterized using a profilometer (Fig. 4C). A small ridge with a height of $7 \mu \mathrm{m}$ was presented at the healed surface. It
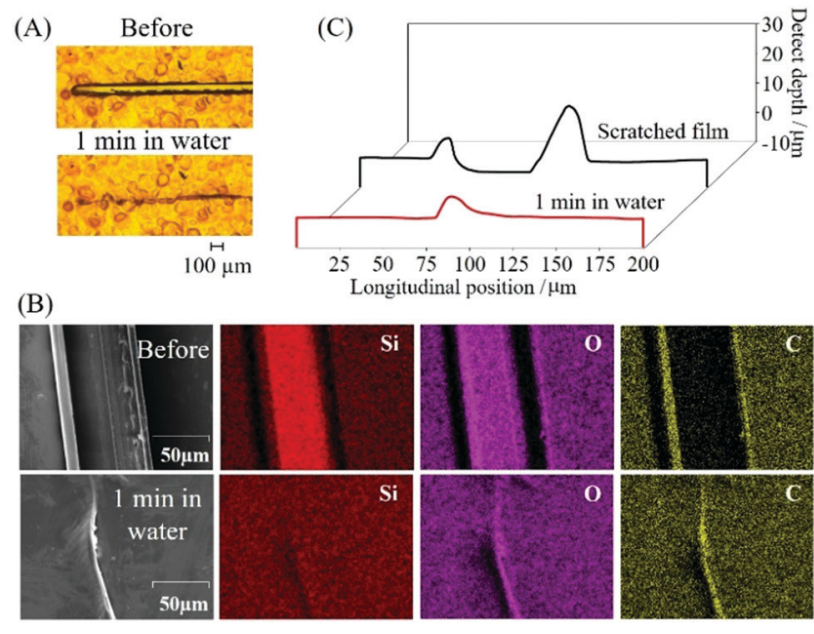

Fig. 4 Microscopic images (A), SEM images and elemental mapping data (B) and temporal evolution of the depth along the length (C) of the engraved and healed 1.80 PVA-SWF film by immersion in water for $1 \mathrm{~min}$.

may be due to 2 possible reasons: (1) the diffusion rate of PVA at the middle of the interlayer space was different from PVA adsorbed at the surface of SWF and (2) the healing was achieved within $1 \mathrm{~min}$, so longer time is required for the full recovery. Nevertheless, the re-healing by scratching the film at the same area and the subsequent exposure in water for $1 \mathrm{~min}$ was seen for 10 times (Fig. S2, ESI $\dagger$ ). The self-healing of PVA-SWF hybrid was shown in various aqueous conditions as cold water $\left(2^{\circ} \mathrm{C}\right)$, steam, sea water, acidic solution $(\mathrm{HCl} \mathrm{pH}=1)$ and basic solution $(\mathrm{NaOH}, \mathrm{pH}=14)$, as shown in the photographs (Fig. 5).

The effects of the film thickness on the healing property were studied, and the results are summarized in Fig. S3 (ESI $\dagger$ ). No healing was observed when the thickness of the film was $1 \mu \mathrm{m}$. The healing of the 1.80 PVA-SWF with a thickness of $2 \mu \mathrm{m}$ was noticed after immersion in water for $30 \mathrm{~min}$, while healing was not completed by prolonging the immersion time to $24 \mathrm{~h}$. The limitation of healing is explained as the adhesion of the PVA-SWF hybrid film with the hydrophilic surface of the 


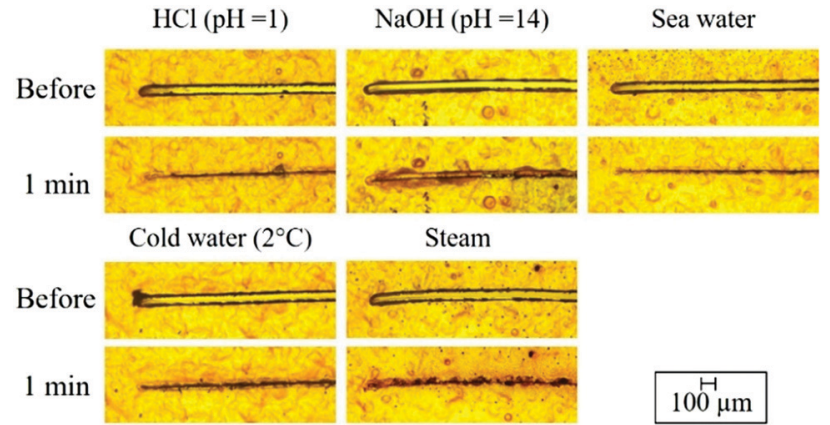

Fig. 5 Microscopic images of engraved and healed 1.80 PVA-SWF films by immersion in $\mathrm{HCl}$ solutions $(\mathrm{pH}=1), \mathrm{NaOH}$ solutions $(\mathrm{pH}=14)$, simulated sea water ( $0.6 \mathrm{M} \mathrm{NaCl}$ solution), cold water and steam for $1 \mathrm{~min}$.

glass substrate. Thus, the driving mechanism for PVA-SWF self-healing is the competition between the interactions of PVA-SWF with water and PVA-SWF with glass substrate. The effect of the film thickness to the self-healing was reported for the PVP complexed with aminopropyl-functionalized layered magnesium silicate, where the film with a thickness over $100 \mathrm{~nm}$ was required for complete healing. ${ }^{27,28}$ Further systematic studies on the healing behavior of the present hybrid as supported films on various substrate as well as free standing films are also worth investigating.

Reported examples of water-induced self-healing polymer coating are summarized in Table 1. Layer-by-layer (LbL) assembly technique ${ }^{54}$ has been used to prepare water-induced selfhealing materials. ${ }^{24,31,55-61}$ Uniform stacking of oppositely charged materials has been obtained by sequential deposition, while it is difficult and time-consuming to produce the thick film by the LbL technique. In the present study, simple casting was employed because the method is simple, ecofriendly and environmentally friendly to obtain uniform polymer-clay films. There was no polymer or clay loss during the film fabrication and the film thickness was easily adjusted by the volume and the concentration of the suspension containing the polymer and clay, which are the additional advantages of the casting method. In addition to the improvement of the mechanical robustness of the polymer through the interactions with the added particles, a chemical crosslinking agent and/or heat treatment was required for the stabilization of nonionic polymers in water as polyethylenedioxythiophene (PEDOT) doped with polystyrene sulfonate (PSS) (PEDOT:PSS), ${ }^{62}$ poly(ethylene glycol) (PEG) ${ }^{25}$ and PVA. ${ }^{30-32}$ Even though the addition of chemical crosslink agents and any thermal treatment were not employed for the insolubilization of PVA, the present 1.80 PVA-SWF hybrid film was stable in water for more than $24 \mathrm{~h}$. If compared with the previous reports on water-induced selfhealing polymers (summarized in Table 1), the present PVA-SWF hybrid has such advantageous aspects as simple preparation, the product stability in water and the fast response of the healing, repeatable healing and ability to heal under various conditions as cold water $\left(2{ }^{\circ} \mathrm{C}\right)$, steam, simulated sea water ( $0.6 \mathrm{M} \mathrm{NaCl}$ solution), acidic solutions $(\mathrm{HCl}, \mathrm{pH}=1)$ and basic solutions $(\mathrm{NaOH}, \mathrm{pH}=14)$. However, the film was liberated from the substrate by a hydrothermal treatment at $100{ }^{\circ} \mathrm{C}$ and $80 \mathrm{kPa}$ for $2 \mathrm{~h}$, which is a next challenge of the present material design. The PVA-SWF hybrid is a possible candidate to be used as a water-based protective coating of

Table 1 Examples of water-induced self-healing polymer coating

\begin{tabular}{|c|c|c|c|c|c|c|c|c|}
\hline Polymer & $\begin{array}{l}\text { Filler/ } \\
\text { content }\end{array}$ & $\begin{array}{l}\text { Crosslinking } \\
\text { agent }\end{array}$ & Method & $\begin{array}{l}\text { Film } \\
\text { thickness }\end{array}$ & $\begin{array}{l}\text { Cut } \\
\text { size }\end{array}$ & Healed condition & Re-healing & Ref. \\
\hline \multirow[t]{3}{*}{ PEIs-PAA } & \multirow[t]{3}{*}{-} & - & \multirow{4}{*}{$\begin{array}{l}\text { Layer-by-layer } \\
\text { technique }\end{array}$} & $34 \mu \mathrm{m}$ & $50 \mu \mathrm{m}$ & In water $5 \mathrm{~min}$ & 5 times & 24 \\
\hline & & \multirow[t]{2}{*}{ Hyaluronic acid } & & $29 \mu \mathrm{m}$ & $29 \mu \mathrm{m}$ & In water $26-34 \mathrm{~min}$ & 5 times & 57 \\
\hline & & & & $58.8 \mu \mathrm{m}$ & $48 \mu \mathrm{m}$ & Drop $0.1 \mathrm{ml}$ water $5 \mathrm{~min}$ & - & 58 \\
\hline b-PEIs-PAA & - & - & & $20 \mu \mathrm{m}$ & $4.3 \mu \mathrm{m}$ & In water $30 \mathrm{~min}$ & 20 times & 59 \\
\hline PEDOT:PSS & - & $\begin{array}{l}\text { Heat } 80,110 \text { and } \\
140{ }^{\circ} \mathrm{C}\end{array}$ & Casting & $1 \mu \mathrm{m}$ & $44 \mu \mathrm{m}$ & Drop $10 \mu \mathrm{l}$ water $150 \mathrm{~ms}$ & - & 62 \\
\hline PVP & $\begin{array}{l}\text { AMP-clay/ } \\
20 \mathrm{wt} \%\end{array}$ & - & Spin coating & $900 \mathrm{~nm}$ & $\begin{array}{l}20-30 \\
\mu \mathrm{m}\end{array}$ & $\geq 50 \%$ RH $36 \mathrm{~h}$ & - & 27 \\
\hline \multirow{4}{*}{$\begin{array}{l}\text { PFOS-PVP- } \\
\text { PEG } \\
\text { PVA }\end{array}$} & & - & Spray coating & $100 \mathrm{~nm}$ & $10 \mu \mathrm{m}$ & $\geq 80 \% \mathrm{RH} 24 \mathrm{~h}$ & - & 28 \\
\hline & - & Tannic acid & Casting & $46.5 \mu \mathrm{m}$ & $50 \mu \mathrm{m}$ & In water $5 \mathrm{~min}$ & 5 times & 25 \\
\hline & $\begin{array}{l}\text { Clay } /<20 \\
\text { wt } \%\end{array}$ & Tannic acid & Doctor blade & $42 \mu \mathrm{m}$ & $50 \mu \mathrm{m}$ & In water $30 \mathrm{~min}$ & 6-12 times & 32 \\
\hline & $\begin{array}{l}\text { Clay/35-74 } \\
\text { wt } \%\end{array}$ & - & Casting & $5 \mu \mathrm{m}$ & $30 \mu \mathrm{m}$ & $\begin{array}{l}\text { In water, } \mathrm{HCl}, \mathrm{NaOH} \text {, steam, } \mathrm{NaCl} \text {, } \\
\text { cold water } 1 \mathrm{~min}\end{array}$ & $\begin{array}{l}\text { More than } 10 \\
\text { times }\end{array}$ & $\begin{array}{l}\text { This } \\
\text { work }\end{array}$ \\
\hline
\end{tabular}

Abbreviations; PEIs = poly(ethylenimine), bPEIs = branched polyethylenimine, PAA = poly(acrylic acid), PEDOT:PSS = polyethylenedioxythiophene doped with polystyrene sulfonate, PVP = polyvinylpyrrolidone, PEG = polyethylene glycol, PFOS = perfluorooctanesulfonic acid potassium salt, GO = graphene oxide, AMP-clay = aminopropyl-functionalized layered magnesium silicate. 
material to protect not only from the mechanical damage but also from environmental exposure $\left(\mathrm{O}_{2}\right.$ and $\left.\mathrm{H}_{2} \mathrm{O}\right)$. Different coating methods such as doctor blading, spray coating and dip coating are applicable. However, the adhesion of the coating should be evaluated before the application, so that the coating of the hybrids on various substrates is worth investigating.

The adhesion of 1.80 PVA-SWF to the substrate was further confirmed by the fabrication of the hybrid as a hook's adhesive. The thicknesses of 15 and $45 \mu \mathrm{m}$ were required for the attachment of the hook on the glass and frosted glass (surface roughness of $14 \pm 2 \mu \mathrm{m}$ ), respectively. By using the thickness of $45 \mu \mathrm{m}$, the hook that attached to the glass and frosted glass could hang $500 \mathrm{~g}$ of iron balls for more than $24 \mathrm{~h}$ (Fig. S4B and $\mathrm{E}, \mathrm{ESI} \dagger$ ). After that, the hooks were pulled out from the glass and frosted glass windows (Video S3 and S4, ESI $\dagger$ ). There are no PVA-SWF films remaining on the windows, while the surface roughness of the film changed after the attachment to the frosted glass (Fig. S4C and F, ESI $\dagger$ ). The surface roughness of the film before and after attachment to the frosted glass was evaluated using a profilometer (Fig. S5, ESI $\dagger$ ). The roughness of the film increased from $0.9 \pm 0.2 \mu \mathrm{m}$ to $8 \pm 2 \mu \mathrm{m}$, indicating the softness property of the PVA-SWF surface. This experiment indicated the flexibility of the PVA-SWF film upon mechanical compressing (manual compressing) to adjust the shape to some extent for better adhesion. These observations suggested the importance of the thickness of the coating to be adhered to the substrates with varied surface roughness. In other words, the strength of adhesion can be varied by the roughness of the surface to be attached. In addition, the effect of the composition on adhesion was evaluated using a tensile tester (shear lap test). The relationship between shear load and the displacement is shown in Fig. S9 (ESI $\dagger$ ). The average shear strength for the separation of the plates was $105.9 \pm 11.9$ and $38.9 \pm 4.2 \mathrm{kPa}$ for 0.36 and 1.80 PVA-SWFs, respectively. Adhesion of the present hybrids to various substrates and under different conditions is being investigated in our laboratory to clarify the possible application of the present films.

\section{Conclusions}

A Water-induced self-healing hybrid has been designed from a water-soluble polymer, poly(vinyl alcohol), with a smectite clay. The preparation was based on simple mixing of the components in an aqueous medium and subsequent casting on a glass substrate. Sedimentation induced the orientation of PVA intercalated SWF platy particles parallel to the substrate. The poly(vinyl alcohol)-clay films were stably adhered to the substrate upon soaking in water for more than $24 \mathrm{~h}$. The healing was achieved from the immersion of the scratched poly(vinyl alcohol)-clay hybrid film under different conditions as water $\left(25{ }^{\circ} \mathrm{C}\right)$, cold water $\left(2{ }^{\circ} \mathrm{C}\right), \mathrm{HCl}$ solutions $(\mathrm{pH}=1), \mathrm{NaOH}$ solutions $(\mathrm{pH}=14)$, steam, and $\mathrm{NaCl}$ seawater within $1 \mathrm{~min}$. The damage-healing cycle was repeated for 10 times.

\section{Conflicts of interest}

There are no conflicts to declare.

\section{Acknowledgements}

This work was supported by the Research Chair Grant 2017 (Grant number FDA-CO-2560-5655) from the National Science and Technology Development Agency (NSTDA), and the Program Management Unit for Human Resources \& Institutional Development, Research and Innovation, NXPO (Grant number B05F630117). Thailand. One of the authors (A. P. T.) acknowledges Vidyasirimedhi Institute of Science and Technology for the scholarship to her PhD study. The authors appreciate Kunimine Ind. Co., Ltd for the donation of the clay samples and Prof. Vinich Promarak of the Vidyasirimedhi Institute of Science and Technology (VISTEC) for the use of profilometer.

\section{References}

1 T. Chang, F. Panhwar and G. Zhao, Adv. Mater. Interfaces, 2020, 7, 1901959.

2 S. Wang and M. W. Urban, Nat. Rev. Mater., 2020, 5, 562-583.

3 L. Zhai, A. Narkar and K. Ahn, Nano Today, 2020, 30, 100826.

4 Y. Huang, M. Zhu, Y. Huang, Z. Pei, H. Li, Z. Wang, Q. Xue and C. Zhi, Adv. Mater., 2016, 28, 8344-8364.

5 L. Zhang, B. K. Chandran and X. Chen, in Soft Matter Nanotechnology, ed. Z. Chen and H. Fuchs, John Wiley \& Sons, Inc., United States, 2015, pp. 401-418.

6 Z. Ma, S. Li, H. Wang, W. Cheng, Y. Li, L. Pan and Y. Shi, J. Mater. Chem. B, 2019, 7, 173-197.

7 T. P. Huynh and H. Haick, Nanomaterials Design for Sensing Applications, Elsevier, Netherland, 2019, pp. 325-339.

8 Z. Wang, L. Scheres, H. Xia and H. Zuilhof, Adv. Funct. Mater., 2020, 30, 1908098.

9 F. Zhang, P. Ju, M. Pan, D. Zhang, Y. Huang, G. Li and X. Li, Corros. Sci., 2018, 144, 74-88.

10 R. Duarah, A. Deka and N. Karak, eXPRESS Polym. Lett., 2020, 14, 542-555.

11 R. Gupta, D. Huo, M. White, V. Jha, G. B. Stenning and K. Pancholi, Compos. Commun., 2019, 16, 67-78.

12 X. Cui, J. Chen, Y. Zhu and W. Jiang, Chem. Eng. J., 2020, 382, 122823.

13 Y. Zhu, K. Cao, M. Chen and L. Wu, ACS Appl. Mater. Interfaces, 2019, 11, 33314-33322.

14 C. Lu, Y. Liu, X. Liu, C. Wang, J. Wang and F. Chu, ACS Sustainable Chem. Eng., 2018, 6, 6527-6535.

15 R. Vaiyapuri, B. W. Greenland, H. M. Colquhoun, J. M. Elliott and W. Hayes, Polym. Chem., 2013, 4, 4902-4909.

16 C. C. Corten and M. W. Urban, Adv. Mater., 2009, 21, 5011-5015.

17 W. Peng, Z. P. Zhang, M. Z. Rong and M. Q. Zhang, ACS Appl. Mater. Interfaces, 2020, 12, 27614-27624. 
18 Y. Li, L. Liang, C. Liu, Y. Li, W. Xing and J. Sun, Adv. Mater., 2018, 30, 1707146.

19 T. P. Huynh, M. Khatib and H. Haick, Adv. Mater. Technol., 2019, 4, 1900081.

20 B. K. Ahn, D. W. Lee, J. N. Israelachvili and J. H. Waite, Nat. Mater., 2014, 13, 867.

21 N. N. Xia, M. Z. Rong and M. Q. Zhang, J. Mater. Chem. A, 2016, 4, 14122.

22 Y. Cao, H. Wu, S. I. Allec, B. M. Wong, D. S. Nguyen and C. Wang, Adv. Mater., 2018, 30, 1804602.

23 E. V. Skorb and D. V. Andreeva, Polym. Chem., 2013, 4, 4834-4845.

24 X. Wang, F. Liu, X. Zheng and J. Sun, Angew. Chem., Int. Ed., 2011, 50, 11378-11381.

25 Y. Du, W. Z. Qiu, Z. L. Wu, P. F. Ren, Q. Zheng and Z. K. Xu, Adv. Mater. Interfaces, 2016, 3, 1600167.

26 J. Ren, H. Xuan and L. Ge, Eur. Polym. J., 2017, 93, 521-529.

27 M. W. England, C. Urata, G. J. Dunderdale and A. Hozumi, ACS Appl. Mater. Interfaces, 2016, 8, 4318.

28 T. Sato, G. J. Dunderdale and A. Hozumi, Langmuir, 2020, 36, 7439-7446.

29 Y. Dou, A. Zhou, T. Pan, J. Han, M. Wei, D. G. Evans and X. Duan, Chem. Commun., 2014, 50, 7136-7138.

30 Y. Li, X. Fang, Y. Wang, B. Ma and J. Sun, Chem. Mater., 2016, 28, 6975-6984.

31 X. Qi, D. Zhang, Z. Ma, W. Cao, Y. Hou, J. Zhu, Y. Gan and M. Yang, ACS Nano, 2018, 12, 1062-1073.

32 X. Qi, Y. Hou and M. Yang, Adv. Funct. Mater., 2019, 29, 1903984.

33 J. W. Kim, H. Park, G. Lee, Y. R. Jeong, S. Y. Hong, K. Keum, J. Yoo, M. S. Kim and J. S. Ha, Adv. Funct. Mater., 2019, 29, 1905968.

34 K. J. Imwiset, A. P. Teepakakorn, P. M. Saengdet, C. B. Tirayaphanitchkul and M. Ogawa, in Concepts and Design of Materials Nanoarchitectonics, ed. O. Azzaroni and K. Ariga, Royal Society of Chemistry, United Kingdom, 2021, in press.

35 B. K. G. Theng, Formation and properties of clay-polymer complexes, Elsevier, Netherland, 2012.

36 K. Haraguchi, K. Uyama and H. Tanimoto, Macromol. Rapid Commun., 2011, 32, 1253-1258.

37 K. Haraguchi and T. Takehisa, Adv. Mater., 2002, 14, 1120-1124.

38 K. Haraguchi, R. Farnworth, A. Ohbayashi and T. Takehisa, Macromolecules, 2003, 36, 5732-5741.

39 D. J. Greenland, J. Colloid Sci., 1963, 18, 647-664.
40 M. M. Zagho and M. M. Khader, J. Mater. Sci. Chem. Eng., 2016, 4, 20-31.

41 M. Sohmiya, S. Omata and M. Ogawa, Polym. Chem., 2012, 3, 1069-1074.

42 M. Ogawa, M. Inagaki, N. Kodama, K. Kuroda and C. Kato, J. Phys. Chem., 1993, 97, 3819-3823.

43 M. Ogawa, M. Tsujimura and K. Kuroda, Langmuir, 2000, 16, 4202-4206.

44 H. van Olphen and J. J. Fripiat, Data Handbook for Clay Minerals and Other Non-Metallic Minerals, Pergamon Press, United Kingdom, 1979.

45 M. Mohsen-Nia and H. Modarress, J. Adhes. Sci. Technol., 2016, 20, 1273-1280.

46 E. S. Tsurko, P. Feicht, C. Habel, T. Schilling, M. Daab, S. Rosenfeldt and J. Breu, J. Membr. Sci., 2017, 540, 212-218.

47 Y. Song, J. Gerringer, S. Qin and J. C. Grunlan, Ind. Eng. Chem. Res., 2018, 57, 6904-6909.

48 A. A. Sapalidis, F. K. Katsaros, T. A. Steriotis and N. K. Kanellopoulos, J. Appl. Polym. Sci., 2012, 123, 1812-1821.

49 M. Lim, D. Kim, H. Han, S. B. Khan and J. Seo, Polym. Compos., 2015, 36, 660-667.

50 M. Kokabi, M. Sirousazar and Z. M. Hassan, Eur. Polym. J., 2007, 43, 773-781.

51 H. Tetsuka, T. Ebina, H. Nanjo and F. Mizukami, J. Mater. Chem., 2007, 17, 3545-3550.

52 Y. H. Kim and R. P. Wool, Macromolecules, 1983, 16, 1115-1120.

53 R. P. Wool and K. M. O’Connor, J. Appl. Phys., 1981, 52, 5953-5963.

54 G. Decher, Science, 1997, 277, 1232-1237.

55 Y. Song, K. P. Meyers, J. Gerringer, R. K. Ramakrishnan, M. Humood, S. Qin, A. A. Polycarpou, S. Nazarenko and J. C. Grunlan, Macromol. Rapid Commun., 2017, 38, 1700064.

56 M. Humood, K. Polychronopoulou, Y. Song, J. C. Grunlan and A. A. Polycarpou, Polymer, 2017, 131, 169-178.

57 Y. Wang, T. Li, S. Li and J. Sun, Chem. Mater., 2015, 27, 8058-8065.

58 Y. Li, S. Chen, M. Wu and J. Sun, Adv. Mater., 2012, 24, 4578-4582.

59 X. Wang, Y. Wang, S. Bi, Y. Wang, X. Chen, L. Qiu and J. Sun, Adv. Funct. Mater., 2014, 24, 403-411.

60 X. Huang, M. J. Bolen and N. S. Zacharia, Phys. Chem. Chem. Phys., 2014, 16, 10267-10273.

61 Y. Li, S. Chen, X. Li, M. Wu and J. Sun, ACS Nano, 2015, 9, 10055-10065.

62 S. Zhang and F. Cicoira, Adv. Mater., 2017, 29, 1703098. 